\title{
The role of regular physical exercise for enhancement of long-term memory in the elderly: a review of recent evidences
}

\section{O papel do exercício físico regular na melhora da memória de longo prazo em idosos: uma revisão de evidências recentes}

\author{
Helen Lidiane Schimidta, Pâmela Billig Mello Carpes ${ }^{b}$, Felipe Pivetta Carpes ${ }^{c}$ \\ a Universidade Federal do Pampa, Rio Grande do Sul, Brasil.<hlschimidt@gmail.com> \\ b Universidade Federal do Pampa, Rio Grande do Sul, Brasil. < pamelacarpes@unipampa.edu.br> \\ - Universidade Federal do Pampa, Rio Grande do Sul, Brasil. <felipecarpes@unipampa.edu.br>
}

\section{ARTICLE INFO}

\section{Article history}

Received: 02/09/2015

Accepted: 24/09/2015

\section{Correspondent Author}

Helen Lidiane Schimidt

Universidade Federal do Pampa

BR 472, km 592

Uruguaiana, RS, Brasil

<hlschimidt@gmail.com>

\section{(C) 2015 All rights reserved}

\section{Editors}

Alfredo Cataldo Neto

Irenio Gomes

\begin{abstract}
Aims: We performed a systematic review of recent literature to discuss the role of physical exercise on cognition of the elderly, especially long-term memory (LTM). Source of data: The articles were sought in scientific journals indexed in Medline through PubMed and PubMed Central websites. In the final yield a total of 8 articles was selected. They show that Exercise programs improving LTM in the elderly involved aerobic activities performed 2-3 times per week. LTM improvements were correlated with brain-specific regions changing volume and depend on intensity, performed at least moderately for a minimum of 2.5 to 3 months. Exercise programs to improve LTM require strict control of exercise intensity, while different training duration and weekly sessions seem effective. Conclusions: Training focusing only in walking sessions requires further investigations to ensure its potential in improving LTM in the elderly.
\end{abstract}

KEYWORDS: Physical training; Aging; Learning; Cognition; Memory.

\section{RESUMO}

Objetivos: Nós fizemos uma revisão sistematica da literatura recente para discutir o papel do exercicio fisico na cognição de idosos, especialmente na memória de longo prazo (MLP). Fonte dos dados: Os artigos foram pesquisados em publicações científicas indexadas no Medline através dos sites PubMed e PubMed Central. No final, um total de 8 artigos foram selecionados. Eles mostram que programas de exercicio que melhoram a MLP envolvem atividades aerobicas feitas $2-3$ vezes por semana. Melhoras na MLP estavam relacionadas a específicas regiões cerebrais mudando de volume e dependem da intensidade, sendo feitas ao menos moderadamente por um período mínimo de 2,5 a 3 meses. Programas de exercicio para melhorar MLP requerem um controle rigoroso da intensidade do exercicio, enquanto que diferentes durações dos treinos e das sessões semanais parecem ser efetivas. Conclusões: Treinamento focado somente em sessões de caminhadas precisam ser melhor investigadas para determinar seu potencial de melhorar a MLP em idosos.

PalaVRaS-ChaVe: Treino físico; Envelhecimento; Aprendizado; Cognição; Memória. 


\section{INTRODUCTION}

Physical exercise is a source of health and quality of life in the elderly. It contributes to strength gains ${ }^{1}$, balance improvement ${ }^{2}$, independent locomotion and better general health condition in the elderly ${ }^{3}$. Psychological benefits are also observed in the elderly engaged in programs of regular physical exercise ${ }^{4}$. Besides the benefit of enhancing performance of daily activities, the impact of physical exercise on cognitive function has been extensively investigated in different contexts, and often suggested as positively influencing cognitive function ${ }^{5,6}$. One important cognitive function that continuously brings attention to scientists is longterm memory.

Long-term memory (LTM) plays important roles in the cognitive integrity of the elderly. LTM can last days, months and even years. It requires time for its establishment and consolidation processes, which may take several hours ${ }^{7}$. Along this process, increase in brain gene expression and protein synthesis is observed. While LTM is in formation, short-term memory, which lasts up to 6 hours, is still available? The normal aging process during the life span can impair LTM formation/ consolidation $^{8}$. Such impairments will negatively impact the health status and quality of life in the elderly, limiting independence and security in the performance of daily activities, such as cooking ${ }^{9}$. A number of studies addressed the effects of exercise on memory in the elderly, and at least two recent reviews have extensively described the relationships between exercise and LTM ${ }^{5,6}$. In fact, most of the studies on this topic are animal studies ${ }^{10}$.

Additionally, an expressive number of articles consider the acute effects of exercise on the memory; for examples, see additional references ${ }^{11,12}$ and a recent review $^{6}$. It is known that among the acute effects of exercise are the release of catecholamine ${ }^{13}$ and arousal manipulation, which may contribute to speed up or up regulate specific brain mechanisms related to cognitive processes ${ }^{14,15}$. However, such effects can be transient, sometimes not related to permanent gains, and not directly related to physical exercise effects, but to effects of any intervention that manipulates arousal ${ }^{16}$. The evidence seems to support that acute effect of exercise on acquisition of new memories can be very positive in the elderly, and long-term exercise would contribute to responses of the molecular machinery responsible for memory processing ${ }^{6}$.

Although we are able to find some reviews addressing memory processes in the elderly; for example, see additional references ${ }^{10,17,18}$, most of them present outcomes limited to particular groups, such as Alzheimer patients. Discussing a particular group affected by a disease is important, but presents a significant limitation when trying to extrapolate these results to the independent elderly. Although the incidence of cognitive impairments is high in late age, we cannot neglect the number of elderly carrying on daily activities without such major cognitive deficits.

We found recent reviews addressing the role of physical exercise for enhancing memory in the elderly without cognitive impairment ${ }^{5,6}$. Most of the studies included in those previous reviews considered a larger time window than we considered in the present review, but the number of included articles still was relatively low, i.e., 22 and 19 articles for acute and long-term effects of exercise, respectively ${ }^{6}$, and 11 articles addressing the relationships between cardiorespiratory fitness and long-term memory ${ }^{5}$. If recent investigations considered previous evidences and suggestions when designing interventions in the elderly is still unknown. Furthermore, characteristics of recent interventions to improve LTM in the elderly by means of physical training have not been reviewed. Therefore, here we conducted a systematic review of studies addressing the effects of physical exercise on LTM in the elderly. Through this systematic review we tried to gather the literature of current exercises programs that aimed to improve long-term memory in the elderly and to present their main results and clinical application, more specifically, discussing the exercise configurations and its specific effects on LTM in independent elderly.

From a clinical perspective, human research still raises questions concerning how exercise can be used to improve LTM or to minimize losses related to the expected aging process. Based in the controversial results in the literature, our systematic review discusses this topic in light of studies that trained the elderly and evaluated their cognitive function in well-controlled conditions. The findings of our systematic review provide important information that can help in the clinical decision of exercise administration in the elderly. More than describing exercise interventions and its main results, our systematic analysis suggests some characteristics that interventions based in physical training should include in attempting to increase the chances of success in the purpose of improving LTM through exercise.

\section{MATERIALS AND METHODS}

\section{Data sources and searches}

We analyzed relevant articles published in scientific journals indexed in Medline searched through PubMed and PubMed Central websites. Only articles published 
as full-text between January 1st 2005 and December 29th 2014 were considered. Comprehensive reviews were performed until $2005(5,6)$, and this is the main reason we focused on publications from the last decade. The following combinations of keywords and Mesh Terms were used for the searches:

- In PubMed: "(("long term memory" $[\mathrm{MeSH}$ Terms] OR "memory"[All Fields]) AND ("aged" [MeSH Terms] OR "aged"[All Fields] OR "elderly"[All Fields]) AND ("exercise" [MeSH Terms] OR "exercise"[All Fields])) AND (Journal Article[ptyp] AND "2005/01/01"[PDat]: "2014/12/29"[PDat] AND "humans"[MeSH Terms])"

- In PubMed Central: "((((("long term memory” [MeSH Terms] OR "memory"[All Fields]) AND ("aged"[MeSH Terms] OR "aged" [All Fields] OR "elderly"[All Fields])) AND ("exercise" [MeSH Terms] OR "exercise"[All Fields])) AND (“2004/01/01”[PrintPubDate]: "2014/"[PrintPubDate])) AND ("men"[MeSH Terms] OR "men"[All Fields])) AND ("women" [MeSH Terms] OR “women”[All Fields])”

\section{Study identification}

Original articles investigating the effects of systematic physical exercise on at least one parameter of LTM in the independent elderly, as define by age 65 or higher, without cognitive impairments, were included in this review. Cognitive status was ensured based on the information presented by the authors in the included articles, or on information of minimental score higher than 24. To be included, papers had to be published as a journal article, involving experiments with humans, written in English, and discussing the effects of physical exercise training on LTM, not only acute effects of exercise; paper should present information on intensity, weekly frequency, and duration of the sessions performed. Case studies, pilot studies and papers considering subjects with some neurological impairment that could significantly affect memory processes (for example, Alzheimer disease) were not eligible. All processes of search, selection and review of the papers were conducted by at least two independent authors.

First, studies were selected considering their titles and abstracts. In this phase, concordance between reviewers was not mandatory. Afterwards, overlapping papers from different bases were excluded. Inclusion and exclusion criteria were applied for the rest of the papers, and those that fulfilled the aforementioned criteria were included. When only the abstract did not permit to fully decide the inclusion or exclusion of the paper, the full text was checked. A third author solved any discrepancies between the two independent reviewers.

\section{Quality assessment}

We assessed the quality of individual studies by using a standardized form (for details, see the supplemental file) considering scores ranging from 0 to 1 (1 means better quality). Two independent reviewers performed the initial screening and extraction procedures. Then, another investigator independently assessed all articles satisfying the inclusion criteria. Whenever there was a disagreement, it was solved by collective discussion among the investigators.

\section{Main outcomes}

We extracted information about the clarity of the study's purpose, participant details (including sample size, age, gender, health status), recruitment and sampling methods, presence of inclusion and exclusion criteria, control of co-variants in the data analysis, key outcome variables, methodological approach, reliability of the method used, key findings supported by the main results, and practical implications.

\section{RESULTS}

\section{Yield}

The initial search returned 2,670 articles. After the first round of exclusion, 1,741 articles had the abstract and/or full text read to identify if they filled exclusion and inclusion criteria. In the final yield a total of 8 articles remained (Figure 1).

\section{Quality analysis}

A full description of all aspects of the quality assessment is presented as a supplemental file. Each score corresponds to the average from three independent authors. Scores closer to 1 represent a better quality, and closer to 0 a poor quality. Additionally, an average score for each study is included in Table 1 . When the quality analysis from each study was merged, we observed that the average \pm standard deviation for the quality assessment of the included papers was $0.85 \pm 0.12$.

\section{Characteristics of the included studies}

The main characteristics of the articles included in this systematic review are summarized in Table 1. Further details on the exercise programs and outcomes related to LTM are presented in Table 2. Details of the memory tests conducted in these articles can be reviewed in a recent publication (6). 


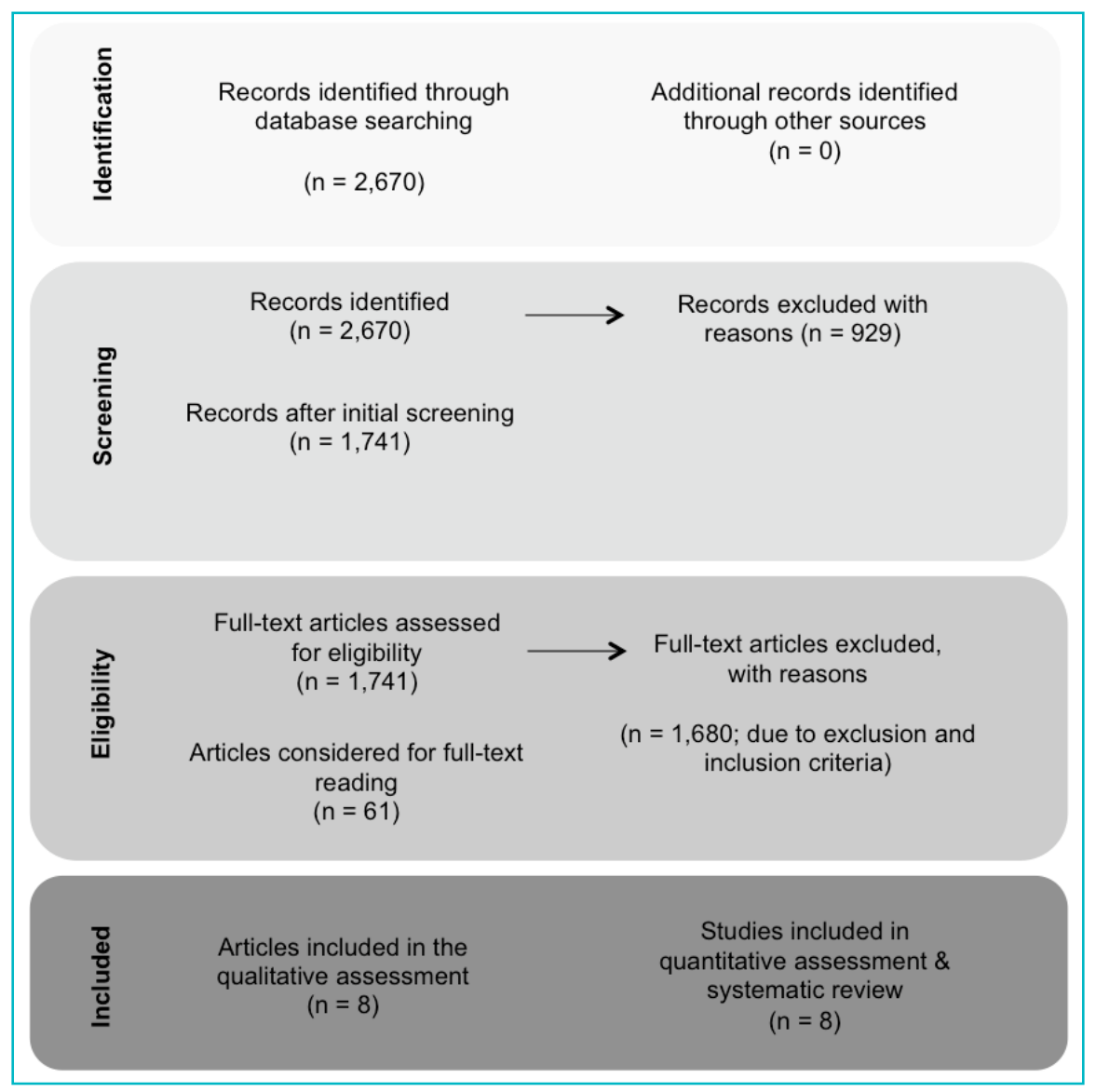

Figure 1

Table 1. Main characteristics of the studies included in this systematic review.

\begin{tabular}{|c|c|c|c|c|c|c|}
\hline \multirow{2}{*}{ Studies } & \multirow{2}{*}{ Study design } & \multirow{2}{*}{$\begin{array}{c}\text { Quality assessment } \\
\text { Average score }\end{array}$} & \multicolumn{3}{|c|}{ Elderly participants } & \multirow{2}{*}{ Cognitive testing* } \\
\hline & & & $\mathbf{n}$ & age & gender & \\
\hline Mc Daniel et al., 2014 & I & 0.92 & 74 & $65 \pm 6$ & $\mathrm{M}, \mathrm{F}$ & $\begin{array}{l}\text { Cooking Breakfast, Virtual Week, Memory for } \\
\text { Health Information }\end{array}$ \\
\hline Tseng et al., 2013 & $\mathrm{C}$ & 0.69 & 24 & $73 \pm 5$ & $\mathrm{M}, \mathrm{F}$ & $\begin{array}{l}\text { Executive function using Delis-Kaplan Executive } \\
\text { Function System, Trail Making Test, Stroop Color } \\
\text { Word Test; Declarative memory using California } \\
\text { Verbal Learning Test-II, Working Memory, and } \\
\text { processing speed and reaction time using Automated } \\
\text { Neuropsychological Assessment Metrics Battery }\end{array}$ \\
\hline Theill et al., 2013 & I & 0.77 & 63 & $72 \pm 5$ & $\mathrm{M}, \mathrm{F}$ & $\begin{array}{l}\text { Cognitive transfer including selective attention, } \\
\text { paired-associates learning, executive control, reasoning, } \\
\text { memory span, information processing speed; } \\
\text { motor-cognitive dual task; verbal working memory. }\end{array}$ \\
\hline Langlois et al., 2012 & I & 0.92 & 83 & $66 \pm 6$ & $\mathrm{M}, \mathrm{F}$ & $\begin{array}{l}\text { MMSE, abstract verbal reasoning, processing speed, } \\
\text { Trail Making Test, modified Stroop Color Word Test, } \\
\text { working memory, episodic memory, and executive } \\
\text { function }\end{array}$ \\
\hline Kamegaya et al., 2012 & I & 0.73 & 30 & $74 \pm 5$ & $\mathrm{M}, \mathrm{F}$ & $\begin{array}{l}\text { Five-cog test (attention, memory, visuospatial function, } \\
\text { language and reasoning) and Wechsler Digit Symbol } \\
\text { Substitution Test }\end{array}$ \\
\hline Ruscheweyh et al., 2011 & I & 0.99 & 62 & $60 \pm 6$ & $\mathrm{M}, \mathrm{F}$ & $\begin{array}{l}\text { Episodic memory performance } \\
\text { Beck's Depression Inventory }\end{array}$ \\
\hline Erickson et al., 2011 & $\mathrm{RCT}$ & 0.99 & 120 & $66 \pm 6$ & $\mathrm{M}, \mathrm{F}$ & Spatial memory task \\
\hline Uffelen et al., 2009 & $\mathrm{RCT}$ & 0.77 & 152 & $75 \pm 3$ & $\mathrm{M}, \mathrm{F}$ & $\begin{array}{l}\text { Mini Mental State Examination, Auditory Verbal } \\
\text { Learning Test, Verbal Fluency Test, Digital Symbol } \\
\text { Substitution Test, Abridged Stroop Color Word Test }\end{array}$ \\
\hline
\end{tabular}

Age is presented for mean \pm standard deviation of the elderly included in the study.

n: number of participants; I: interventional study; C: cross-sectional; RCT: randomized controlled trial; M: male; F: female.

* Additional detail on the cognitive tests is available in the papers cited in this systematic review. 
Table 2: Main characteristics of the exercises programs described in the studies included in this systematic review.

\begin{tabular}{|c|c|c|c|c|c|c|}
\hline Studies & Training programs & $\begin{array}{l}\text { Weekly } \\
\text { frequency }\end{array}$ & $\begin{array}{c}\text { Session } \\
\text { duration }\end{array}$ & Exercise intensity & $\begin{array}{l}\text { Program } \\
\text { duration }\end{array}$ & Effects on memory* \\
\hline Mc Daniel et al., 2014 & $\begin{array}{l}\text { Treadmill walking } \\
\text { or bicycle program } \\
\text { combined or not } \\
\text { with cognitive } \\
\text { training }\end{array}$ & 3 & $\begin{array}{l}\text { Progressive } \\
\text { from } 15 \text { to } \\
50 \text { minutes }\end{array}$ & $\begin{array}{l}\text { Progressive from } \\
50-60 \% \text { to } 65- \\
85 \% \text { of HRR, or } \\
\text { Borg's scale from } \\
12-12 \text { to } 15-16\end{array}$ & $6 \mathrm{~m}$ & $\begin{array}{l}\text { Cognitive training but not aerobic } \\
\text { exercise improves prospective } \\
\text { memory. Single cognitive or } \\
\text { aerobic training did not improve } \\
\text { coordinating multiple tasks and } \\
\text { retrospective memory }\end{array}$ \\
\hline Tseng et al., 2013 & $\begin{array}{l}\text { Endurance training } \\
\text { performed for at } \\
\text { least } 15 \text { years prior }\end{array}$ & ND & ND & ND & $180 \mathrm{~m}$ & $\begin{array}{l}\text { Long-term training improves } \\
\text { executive function and semantic } \\
\text { memory processing. Cognitive } \\
\text { performance is similar between } \\
\text { elderly and young adults }\end{array}$ \\
\hline Theill et al., 2013 & $\begin{array}{l}\text { Treadmill walking } \\
\text { combined or not } \\
\text { with a cognitive } \\
\text { task }\end{array}$ & 2 & 40 minutes & $\begin{array}{l}60-80 \% \text { of } \\
\text { maximal heart } \\
\text { rate for age } \\
(220 \text { minus age })\end{array}$ & $2.5 \mathrm{~m}$ & $\begin{array}{l}\text { Simultaneous cognitive and } \\
\text { physical training improves } \\
\text { cognitive performance. Single } \\
\text { exercise cognitive training only } \\
\text { improves working memory and } \\
\text { executive control tasks }\end{array}$ \\
\hline Langlois et al., 2012 & $\begin{array}{l}\text { Aerobic training } \\
\text { followed by a short } \\
\text { period of strength } \\
\text { training }\end{array}$ & 3 & 60 minutes & $\begin{array}{l}\text { Moderate to hard } \\
\text { (Borgs' scale) }\end{array}$ & $3 \mathrm{~m}$ & $\begin{array}{l}\text { Exercise improves processing } \\
\text { speed, working memory, and } \\
\text { executive function }\end{array}$ \\
\hline Kamegaya et al., 2012 & $\begin{array}{l}\text { Body flexibility, } \\
\text { strength and } \\
\text { balance, and } \\
\text { endurance }\end{array}$ & 1 & 45 minutes & ND & $3 \mathrm{~m}$ & $\begin{array}{l}\text { Exercise improves recall task } \\
\text { included in the Five-cog test } \\
\text { and the Wechsler Digit Symbol } \\
\text { Substitution Test, without } \\
\text { improvements in physical } \\
\text { conditioning }\end{array}$ \\
\hline Ruscheweyh et al., 2011 & $\begin{array}{l}\text { Nordic walking or } \\
\text { gymnastics }\end{array}$ & $3-5$ & 50 minutes & $\begin{array}{l}\text { Nordic walking } \\
\text { at } 50-60 \% \text { of } \\
\text { maximal exertion; } \\
\text { Gymnastics at } \\
30-40 \% \text { of } \\
\text { maximal exertion }\end{array}$ & $6 \mathrm{~m}$ & $\begin{array}{l}\text { Increases in physical activity } \\
\text { were positively associated with } \\
\text { increases in memory score } \\
\text { regardless of exercise intensity }\end{array}$ \\
\hline Erickson et al., 2011 & Walking program & ND & $\begin{array}{l}\text { Progressive } \\
\text { from } 10 \text { to } \\
40 \text { minutes }\end{array}$ & $\begin{array}{l}\text { Walking: from } \\
50-60 \text { to } 60-75 \% \\
\text { of the maximal } \\
\text { HRR }\end{array}$ & $12 \mathrm{~m}$ & $\begin{array}{l}\text { Exercise training increases size } \\
\text { of the hippocampus, leading to } \\
\text { improvements in spatial memory }\end{array}$ \\
\hline Uffelen et al., 2009 & Walking exercise & 2 & 60 minutes & $\begin{array}{l}3 \text { MET and aiming } \\
\text { at low to moderate } \\
\text { intensity }\end{array}$ & $12 \mathrm{~m}$ & $\begin{array}{l}\text { Exercise at low to moderate } \\
\text { intensity improves aerobic } \\
\text { conditioning but was not } \\
\text { associated with changes in } \\
\text { cognitive performance }\end{array}$ \\
\hline
\end{tabular}

ND: not detailed; m: months; HRR: heart rate reserve.

* Only results reported for $\mathrm{p}<0.05$ were considered.

Five studies ${ }^{19-23}$ found improvements in LTM in response to single physical training, one study ${ }^{24}$ only observed benefits of physical training when it was combined with cognitive training, and two studies ${ }^{9,25}$ did not find benefits of physical exercise on LTM in the independent elderly.

All exercise programs performed in the included articles involved aerobic activities (walking was the most frequent activity included in the training regimen), and the average weekly frequency was 2-3 days, at least. For those not observing any effect of physical exercise on LTM $^{9,25}$, target intensity was described as low to moderate. When exercise was effective for LTM, intensity was described as at least moderate ${ }^{19,21-23}$ or eliciting endurance performance ${ }^{20}$. For two studies we were not able to fully identify the weekly frequency of training ${ }^{19,23}$. Average weekly frequency of exercise was 2-3 times per week, and adherence was controlled to reach at least $70 \%$ of the sessions.

\section{DISCUSSION}

In this systematic review, 8 articles fulfilled the requirements to be included in the quality assessment. 
Their results suggest that LTM can be improved by physical exercise, but the success of interventions will depend on several aspects of the training program. Our review was not able to differentiate effects of different types of exercises since all studies were based in aerobic training. The different conclusions among the included articles raise questions concerning the influence of training configuration on its effects on LTM.

Previous reviews discussed the exercise characteristics that may determine LTM gains. They concluded that there is a lack of evidence to support the assumption that improvements in cognitive function can be attributed to physical exercise due to improvements in cardiovascular fitness, although there is a temporal association between cognitive and fitness gains $^{5}$, as well as acute and long-term exercise may reflect two different strategies to improve memory ${ }^{6}$.

In general, the duration of exercise sessions increases from the beginning to the end of the training intervention, which permits the participant a proper adaptation to the training workload. For most of cases the frequency was of 2-3 days per week, and therefore it was not possible to discriminate the effects of exercise in relation to the weekly frequency of exercise. Similarly, training sessions had similar duration between the different studies (up to 50-60 min; for more details, see Table 2).

Longer exercise programs in general resulted in LTM gains, but longer periods of training did not seem mandatory to improve LTM. The longer period of training considered was 15 years and included endurance intensity. In this case, master athletes were evaluated and the main outcome of the systematic long-term endurance training was an improved executive function and memory, with elderly achieving similar results in comparison to young adults ${ }^{23}$. The shortest period of training resulting in LTM gains had a duration of 3 months ${ }^{20,21}$. Contradictory results were found in the different studies in which elderly were trained during $6^{9,22}$ and 12 months ${ }^{19,25}$. Six months of walking combined or not with cognitive training ${ }^{9}$ did not result in LTM improvement, as observed after similar period of Nordic walking ${ }^{22}$. Also, 12 months of walking at low to moderate intensity ${ }^{25}$ did not improve LTM, as observed after 12 months attending a walking program $^{19}$. Although the different results for the same training durations is curious, explanation for such contradictory results may not relate to the duration of the program itself, but the lower exercise intensity for both trainings that found no LTM improvement after 6 and 12 months of activity. Walking training did not improve physical conditioning for subjects performing at lower intensities ${ }^{25}$. Exercise programs based on walking seemed to result in controversial results, and therefore only walking cannot be ensured as an efficient exercise for cognitive improvement as depicted by LTM in the independent elderly.

Even shorter interventions can provide the elderly with benefits for memory. A short physical training period (20 sessions) combined with a cognitive training promoted good results for LTM in the elderly ${ }^{24}$. In this case, exercise intensity was higher compared to the other studies. Unfortunately, the authors were not able to describe the single-exercise effect, as this experimental condition was missing in the methods. In addition, varying activities during a short period of physical training may play a role for LTM improvements. Therefore it is not clear if the main task performed during the training period is the actual determinant of the benefits for LTM.

How much exercise is need is a good question that we were able to partially answer. However, in addition to the 2-3 sessions of physical exercise per week for least 2.5 or 3 months, which exercise should be performed still questionable. Benefits for LTM were reported after 3 months of training once a week ${ }^{20}$ in a routine of stretching exercise and activities (which were not fully detailed in the article) aiming at development of body flexibility, strength, balance and endurance performed in elderly groups. It is possible that exercise programs not focused on a specific exercise type can provide similar benefits as single activity oriented programs. Exercises based exclusively on walking programs were not effective in improving memory ${ }^{9,24,25}$; such a result was achieved when a walking exercise program had a specific configuration, such as the case of Nordic walking improving $\mathrm{LTM}^{22}$.

It is important not just to start a training program, but also to keep on doing it. Therefore, it is important to know if missing training sessions can impair the benefits expected for LTM in physical training. Most of the studies mentioned controlled adherence to the training sessions and take it into account during the data analysis, considering only those participants that joined a significant number of sessions (for example, at least $70 \%$ of the sessions). However, one study reported that cognition improvement was not significantly associated with session attendance ${ }^{25}$. However, this study ${ }^{25}$ did not find association between exercise and cognitive improvement, most likely because exercise was performed at low to moderate intensities or the lack of adherence control may have influenced the elderly performance. Therefore, it seems to be recommendable that adherence to the training be considered when analyzing data, but more importantly to ensure that the elderly can in fact benefit by attending the physical training. 
If behavioral measures of LTM are positively affected by exercise, some brain adaptations could be expected. A few studies addressed LTM-related neural adaptations to the physical training. Among the neural adaptations associated with improved LTM were increases in gray and white matter concentrations, especially in the hippocampus, prefrontal and cingulate cortex extending into occipital, frontal and parietal cortices. Therefore, we could argue that physical exercise did not influence the different brain regions to the same extent. An increase in the hippocampus volume was observed in the trained elderly ${ }^{19}$. On other hand, a control group (performing only stretching exercises at low intensity) reduced hippocampal volume over one-year ${ }^{19}$. Both groups (walking and stretching) improved spatial memory, which was positively correlated with physical fitness. Elderly engaged in endurance training for a significant period of life $(\sim 15$ years) presented higher gray matter concentrations in the right parietal lobe, occipital lobe, and cerebellum than sedentary elderly ${ }^{23}$. White matter was also higher in the trained elderly than sedentary ones when looking at the parietal, temporal and occipital lobe ${ }^{23}$. Gray matter volume was correlated with physical activity for several cortical areas of elderly trained in the Nordic walking program ${ }^{22}$. Significant correlations between fitness and gray matter volume emerged in the left prefrontal and cingulate cortex extending into occipital cortex ${ }^{22}$. The prefrontal cortex contributes to memory through strategic control over memory retrieval processes within other brain areas, such as the hippocampus and amygdala. Additionally the hippocampus provides outputs to others cortical areas. These feedback pathways allow the retrieval of detailed memories in the hippocampus that constitute strong recollected experiences and recollection memory ${ }^{26}$.

Serum brain-derived neurotrophic factor (BDNF) did not differ between elderly trained for walking and controls, but correlated with hippocampal volume in the exercise group ${ }^{19}$. In addition, serum BDNF was not correlated with spatial memory ${ }^{19}$. It could be related to the fact that the measurements presented are from peripheral BDNF, and, although it can be used as an approximation of central BDNF levels, it does not exactly represent central BDNF levels, because BDNF can cross the blood-brain barrier ${ }^{27}$. The measure of BDNF in the brain most likely could provide a better idea of the impact of physical exercise on LTM, since it seems clear that physical exercise increases brain BDNF levels and BDNF is involved with synaptic plasticity and neurogenesis in neuronal survival ${ }^{28}$. However, such measurements are limited in humans.
Physical exercise may influence LTM due to the increase of neurotrophic factors other than BDNF, such as vascular endothelial growth factor which, when associated to increased brain blood perfusion ${ }^{30}$, could explain memory enhancement. However, such measurements were not performed in the studies included in this systematic review. Moreover, it is still a matter of debate whether peripheral measures of neurotrophic factors, for instance, are indicators of central levels. They definitely measure on a different level than neuroimaging techniques and, therefore, could not replace them.

In one of the included articles, the catecholamines were positively correlated with physical activity levels. A positive correlation of physical activity with dopamine was observed, but not with epinephrine or norepinephrine levels ${ }^{22}$. Although epinephrine and norepinephrine cannot cross the blood brain barrier, the peripheral release of epinephrine and norepinephrine can activate peripheral $\beta$-adrenergic receptors that project to higher areas of the central nervous system involved in the regulation of memory, such as the hippocampus ${ }^{31}$. The mechanics of how physical activity affects LTM are not fully understood. The oxidative stress and inflammation processes, increase of vascularization, release of neurotrophins and catecholamines and increased neurogenesis, especially in the hippocampus, are also mentioned as possible pathways ${ }^{22}$. However, not all of them were investigated in the studies presented in this review.

A tentative representation of the factors most likely related to LTM improvement in response to regular physical training during aging is illustrated in Figure 2.

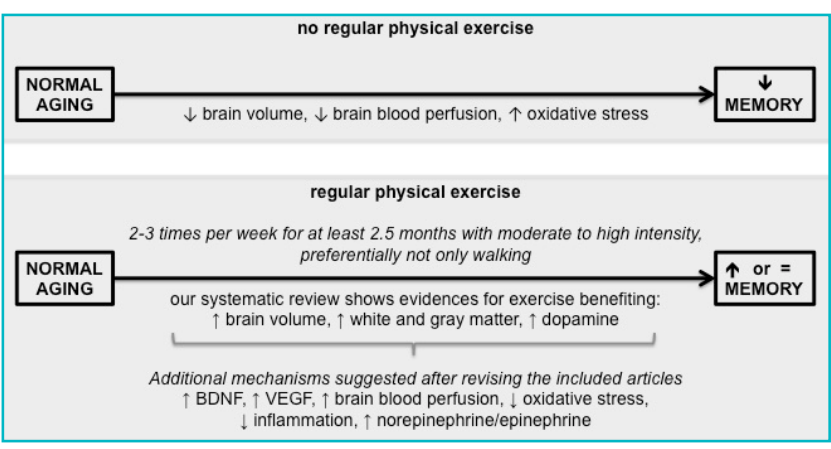

Figure 2

Education (as quantified by years) seems to be an important controlled covariant when comparing trained and control elderly. When trained elderly had lower education than controls, aerobic training per se was not able to improve LTM $^{9}$, while for trained elderly with higher education than control ${ }^{21}$ it resulted 
in improved LTM. For studies considering participants with similar education, physical exercise was positively associated with LTM performance ${ }^{22-24}$, but only when physical exercise was performed at low intensity ${ }^{25}$. Other studies did not discuss whether physical exercise performed alone or in small groups may influence LTM outcomes in different extents. Activities performed in groups most likely can help to promote elders' adherence to training, and adherence was shown to be important in the included articles. In addition, strength exercises, which are very often found as part of fall-prevention programs in the elderly ${ }^{1,4}$, have not been addressed considering its impact on cognitive performance. Other physical exercise programs that are becoming popular among the elderly (Pilates for instance) have not yet been discussed considering LTM benefits.

\section{CONCLUSION}

Exercise programs to improve LTM require strict control of exercise intensity, while different training duration and weekly sessions seem effective. Based on the studies included in this systematic review, training based on walking exercise requires further investigations to ensure its efficacy for enhancement of long-term memory.

\section{ACKNOWLEDGEMENTS}

All authors are with the Graduate Program in Biochemistry from the Federal University of Pampa, Brazil. FPC and PBMC were supported by CAPESBrazil research grants. HLS was supported by a CAPESBrazil doctoral fellowship. Authors wish to express their sincere gratitude and appreciation to those scientists whose works are discussed in this paper. This review reveals a broad approach to a topic that would not exist without their research. The authors declare that they have no conflicts of interest that are directly relevant to the content of this review.

\section{REFERENCES}

1. Cadore EL, Pinto RS, Bottaro M, Izquierdo M. Strength and endurance training prescription in healthy and frail elderly. Aging Dis. 2014;5(3):183-95.

2. Weerdesteyn V, Rijken H, Geurts AC, Smits-Engelsman BC, Mulder T, Duysens J. A five-week exercise program can reduce falls and improve obstacle avoidance in the elderly. Gerontology. 2006;52(3):131-41.

3. Izquierdo M, Cadore EL. Muscle power training in the institutionalized frail: a new approach to counteracting functional declines and very late-life disability. Curr Med Res Opin. 2014;30(7):1385-90.
4. Ko DS, Jung DI, Jeong MA. Analysis of Core Stability Exercise Effect on the Physical and Psychological Function of Elderly Women Vulnerable to Falls during Obstacle Negotiation. Journal of physical therapy science. 2014;26(11):1697-700. Epub 2014/12/02.

5. Angevaren M, Aufdemkampe G, Verhaar HJ, Aleman A, Vanhees L. Physical activity and enhanced fitness to improve cognitive function in older people without known cognitive impairment. The Cochrane database of systematic reviews. 2008(3):CD005381. Epub 2008/07/23.

6. Roig M, Nordbrandt S, Geertsen SS, Nielsen JB. The effects of cardiovascular exercise on human memory: a review with meta-analysis. Neuroscience and Biobehavioral Reviews. 2013;37 (8):1645-66. Epub 2013/06/29.

7. Izquierdo I, Barros DM, Mello e Souza T, de Souza MM, Izquierdo LA, Medina JH. Mechanisms for memory types differ. Nature. 1998;393(6686):635-6.

8. Snigdha S, de Rivera C, Milgram NW, Cotman CW. Exercise enhances memory consolidation in the aging brain. Front Aging Neurosci. 2014;6:3.

9. McDaniel MA, Binder EF, Bugg JM, Waldum ER, Dufault C, Meyer A, et al. Effects of cognitive training with and without aerobic exercise on cognitively demanding everyday activities. Psychology and aging. 2014;29(3):717-30. Epub 2014/09/23

10. Barnes JN. Exercise, cognitive function, and aging. Adv Physiol Educ. 2015;39(2):55-62.

11. Hogan CL, Mata J, Carstensen LL. Exercise holds immediate benefits for affect and cognition in younger and older adults. Psychology and aging. 2013;28(2):587-94. Epub 2013/06/26.

12. Nielson KA, Wulff LL, Arentsen TJ. Muscle tension induced after learning enhances long-term narrative and visual memory in healthy older adults. Neurobiology of learning and memory. 2014;109:144-50. Epub 2014/01/18.

13. Krzeminski K, Cybulski G, Ziemba A, Nazar K. Cardiovascular and hormonal responses to static handgrip in young and older healthy men. European journal of applied physiology. 2012;112(4):1315-25.

14. Nielson KA, Powless M. Positive and negative sources of emotional arousal enhance long-term word-list retention when induced as long as $30 \mathrm{~min}$ after learning. Neurobiology of learning and memory. 2007;88(1):40-7.

15. Nielson KA, Radtke RC, Jensen RA. Arousal-induced modulation of memory storage processes in humans. Neurobiology of learning and memory. 1996;66(2):133-42.

16. Nielson KA, Meltzer MA. Modulation of long-term memory by arousal in alexithymia: the role of interpretation. Conscious Cogn. 2009; 18(3):786-93.

17. Hernandez SS, Sandreschi PF, Silva FC, Arancibia BA, da Silva R, Gutierres PJ, et al. What are the Benefits of Exercise for Alzheimer s Disease? A Systematic Review of Past 10 Years. Journal of aging and physical activity. 2014.

18. Yau SY, Gil-Mohapel J, Christie BR, So KF. Physical exerciseinduced adult neurogenesis: a good strategy to prevent cognitive decline in neurodegenerative diseases? BioMed research international. 2014;2014:403120.

19. Erickson KI, Voss MW, Prakash RS, Basak C, Szabo A, Chaddock L, et al. Exercise training increases size of hippocampus and improves memory. Proceedings of the National Academy of Sciences of the United States of America. 2011;108(7):3017-22. Epub 2011/02/02.

20. Kamegaya T, Maki Y, Yamagami T, Yamaguchi T, Murai T, Yamaguchi H. Pleasant physical exercise program for prevention of cognitive decline in community-dwelling elderly with subjective memory complaints. Geriatrics 
\& gerontology international. 2012;12(4):673-9. Epub 2012/04/04

21. Langlois F, Vu TT, Chasse K, Dupuis G, Kergoat MJ, Bherer L. Benefits of physical exercise training on cognition and quality of life in frail older adults. The journals of gerontology Series B, Psychological sciences and social sciences. 2013;68(3):400-4. Epub 2012/08/30.

22. Ruscheweyh R, Willemer C, Kruger K, Duning T, Warnecke T, Sommer J, et al. Physical activity and memory functions: an interventional study. Neurobiology of aging. 2011;32(7):1304-19. Epub 2009/09/01.

23. Tseng BY, Uh J, Rossetti HC, Cullum CM, Diaz-Arrastia $\mathrm{RF}$, Levine BD, et al. Masters athletes exhibit larger regional brain volume and better cognitive performance than sedentary older adults. Journal of magnetic resonance imaging : JMRI. 2013;38(5):1169-76. Epub 2013/08/03.

24. Theill N, Schumacher V, Adelsberger R, Martin M, Jancke L. Effects of simultaneously performed cognitive and physical training in older adults. BMC neuroscience. 2013;14:103. Epub 2013/09/24.

25. van Uffelen JG, Chinapaw MJ, Hopman-Rock M, van Mechelen W. Feasibility and effectiveness of a walking program for community-dwelling older adults with mild cognitive impairment. Journal of aging and physical activity. 2009;17(4):398-415. Epub 2009/11/27.

26. Preston AR, Eichenbaum H. Interplay of hippocampus and prefrontal cortex in memory. Current biology: CB. 2013;23(17):R764-73. Epub 2013/09/14.

27. Pan W, Banks WA, Fasold MB, Bluth J, Kastin AJ. Transport of brain-derived neurotrophic factor across the blood-brain barrier. Neuropharmacology. 1998;37(12):1553-61.

28. Erickson KI, Miller DL, Roecklein KA. The aging hippocampus: interactions between exercise, depression, and BDNF. The Neuroscientist : a review journal bringing neurobiology, neurology and psychiatry. 2012;18(1):82-97. Epub 2011/05/03.

29. Swain RA, Harris AB, Wiener EC, Dutka MV, Morris HD, Theien BE, et al. Prolonged exercise induces angiogenesis and increases cerebral blood volume in primary motor cortex of the rat. Neuroscience. 2003;117(4):1037-46.

30. Skriver K, Roig M, Lundbye-Jensen J, Pingel J, Helge JW, Kiens B, et al. Acute exercise improves motor memory: exploring potential biomarkers. Neurobiology of learning and memory. 2014;116:46-58. Epub 2014/08/17. 